\title{
Secondary prevention of hypercholesterolaemia: results of an audit conducted in South Wales
}

\author{
L S Cozma, A Ogunko, A Rees
}

\begin{abstract}
Objective-To audit the standards of secondary prevention of coronary heart disease in postmyocardial infarction patients.

Design-Follow up audit, one year after acute admission with myocardial infarction.

Setting-University Hospital.

Subjects-For the initial admission, 153 patients were audited, with 84 patients contacted one year later. Demographic data, treatment status, and cholesterol levels were analysed both on admission and at follow up.

Interventions-Total cholesterol was checked at the audit time either in the hospital or in the doctor's surgery.

Main outcome measures-Statin doses and cholesterol levels.

Results-Ninety six per cent of patients had their lipid profile performed on admission. Eighty three per cent of the patients with total cholesterol $\geqslant 5 \mathrm{mmol} / \mathrm{l}$ were discharged from the hospital on lipid lowering medication. Forty five per cent of the subjects who were followed up had cholesterol levels $\geqslant 5 \mathrm{mmol} / \mathrm{l}$ at 1 year. There was a disproportionate use of low doses of statins (lower than those shown in effective trials: simvastatin 20 to $40 \mathrm{mg}$, pravastatin $40 \mathrm{mg}$ ) with a third of all patients on medication not achieving the targets at one year.

Conclusion-There was a major improvement in the proportion of patients started on treatment compared with figures reported by previous studies. However, the titration of the statin doses to achieve the targets is still unsatisfactory.

(Heart 2000;84:e3)
\end{abstract}

Keywords: audit; hypercholesterolaemia; statins

Large clinical trials with different HMG-CoA reductase inhibitors (statins) have demonstrated that lipid lowering treatment reduces cardiovascular morbidity and overall mortality in patients with established coronary heart disease (CHD). ${ }^{1-3}$ Analysis of prespecified subgroups of patients showed that the benefit was the same regardless of age, sex, or whether the patient had diabetes mellitus. Therefore, the debate about cholesterol lowering has moved on from questions of efficacy and safety to that of implementation. The Joint British recommendations for the prevention of coronary heart disease emphasise that individual CHD risk factors should not be considered in isolation, but that an integrated approach to management should be adopted. ${ }^{4}$ Recent analyses have shown that the cost effectiveness of statin treatment in secondary prevention compares well with other interventions in cardiovascular disease management. ${ }^{56}$ However, there is evidence that the effective delivery of this health care is suboptimal. In the ASPIRE (action on secondary prevention

Accepted 25 April 2000

Table 1 Admission and follow up information

\begin{tabular}{lll}
\hline & Admission $(n=153)$ & Follow up $(n=84)$ \\
\hline Age (years) & Range: 28 to 88 & Range: 36 to 88 \\
Total cholesterol $(\mathrm{mmol} / \mathrm{l})$ & Mean: 61.5 & Mean: 62 \\
Triglycerides $(\mathrm{mmol} / \mathrm{l})$ & Range: 3.3 to 17.3 & Range: 2.9 to 9.2 \\
Cholesterol $\geqslant 5.0 \mathrm{mmol} / 1$ & Range: 0.4 to 28.4 & Range: 0.5 to 11.4 \\
Cholesterol $<5.0 \mathrm{mmol} / 1$ & $123(83.6 \%)$ & $38(45.2 \%)$ \\
Simvastatin $10 \mathrm{mg}$ & $24(16.3 \%)$ & $46(54.7 \%)$ \\
Simvastatin $\geqslant 20 \mathrm{mg}$ & 14 & 7 \\
Pravastatin $40 \mathrm{mg}$ & 47 & 86 \\
Pravastatin $<40 \mathrm{mg}$ & 10 & 12 \\
\hline
\end{tabular}

through intervention to reduce events) study, some $78 \%$ of men and $86 \%$ of women had a cholesterol reading of $\geqslant 5 \mathrm{mmol} / 1 .^{7}$ Therefore, we audited the standards of care of the postmyocardial infarction patient at the University Hospital of Wales, Cardiff, with particular regard to the recommended target of total cholesterol of $<5 \mathrm{mmol} / \mathrm{l}$.

\section{PATIENTS AND METHODS}

Patients were admitted between October 1997 and December 1998 with the diagnosis of acute myocardial infarction (coding ICD 10). A specifically designed form was used to collect the data from the case notes with emphasis on demographic information, treatment status, and cholesterol levels before admission and on discharge.

We contacted subjects one year later, checked the lipid lowering medication status, and arranged a fasting lipid sample. The hospital database was searched for those with lipids measured in the last two months.

\section{Results}

One hundred and fifty three patients were audited for the initial admission. We managed to contact 84 patients at follow up (table 1 ).

Six patients did not have their lipids assessed on admission. Twenty two patients with cholesterol $>5.0 \mathrm{mmol} / 1$ were not started on medication on discharge (seven patients over 75 years old).

The time interval between the acute admission and the audit follow up varied between 6 and 20 months, with a mean of 11.8 months. 
At follow up, 20 patients with cholesterol $>5 \mathrm{mmol} / \mathrm{l}$ were on the same statin dose since being discharged from the hospital.

ANALYSIS OF STATIN DOSAGES

The overwhelming majority of statins used in the treatment were those that have been shown to be effective in clinical trials - that is, simvastatin and pravastatin. However, there is an inconsistency in the Joint British guidelines for coronary prevention. ${ }^{4}$ The clinician is urged to use those HMG-CoA reductase inhibitors that have been shown to be effective in clinical trials, in the doses shown to be effective in those trials. This would require the use of $40 \mathrm{mg}$ of pravastatin and either $20 \mathrm{mg}$ or $40 \mathrm{mg}$ of simvastatin. At the same time, there is advice to titrate the dose of statin to achieve the target total cholesterol of $<5 \mathrm{mmol} / \mathrm{l}$. There is some contradiction inherent in this advice. Analysis of our data suggests that local clinicians are attempting to employ the latter strategy-that is, dose titration, as there is a disproportionate use of the lower doses of both simvastatin and pravastatin.

\section{Discussion}

This audit has focused on the use of a total cholesterol target of $<5 \mathrm{mmol} / 1$ as specified in the Joint British recommendations on prevention of coronary heart disease in clinical practice. ${ }^{4}$

The fact that $96 \%$ of patients had their lipid profile performed on admission is very encouraging and certainly reflects an improvement on the ASPIRE data and on a previous audit of patients undergoing coronary bypass grafting at this hospital in $1994 .^{8}$ However, subsequent management lacks consistency, with almost half of the patients having cholesterol levels above the target limits at follow up. A significant proportion of patients is still not receiving appropriate treatment, with over a third of the patients on suboptimal doses of statins. Clearly, appropriate dietary and lifestyle advice is mandatory but should not be used as an excuse to prevaricate and delay treatment with statins. The latest published guidelines recommend the immediate initiation of statin treatment if the total cholesterol is
$>6 \mathrm{mmol} / \mathrm{l}$. The initial approach would be with dietary modification if the levels of total cholesterol are between 5 and $6 \mathrm{mmol} / \mathrm{l} .{ }^{49}$ All patients should have their lipid profile repeated at six weeks and either appropriate dose titration or commencement of statin treatment if the levels are still $>5 \mathrm{mmol} / \mathrm{l}$. Failure to reach the targets may not reflect ignorance of the evidence, but rather a failure of a particular model of health care delivery. It is sometimes unclear who is responsible for this delivery. In some circumstances, the primary care physician is in the best position to discharge this re sponsibility, while in others it may be more appropriate for the patient to be managed in secondary care. Other models of health care delivery need to be considered, such as nurse practitioner led clinics. The time may have come when all patients sustaining a myocardial infarction should opt in to an ABC management strategy (aspirin, $\beta$ blocker, and cholesterol reducing drugs) unless there are compelling contraindications. Procrastination and therapeutic nihilism should no longer be tolerated.

1 Effect of simvastatin on coronary atheroma: the multicentre anti-atheroma study. Lancet 1994;344:633-8.

2 Sacks FM, Pfeffer MA, Moye LA, et al. The effect of pravastatin on coronary events after myocardial infarction in patients with average cholesterol levels. Cholesterol and recurrent events trial investigators. N Engl f Med 1996;335: 1001-9.

3 Prevention of cardiovascular events and death with pravastatin in patients with coronary heart disease and a broad ange of initial cholesterol levels. The long-term intervenion with pravastatin in ischaemic disease (LIPID) study Group. N Engl f Med 1998;339:1349-57.

4 Joint British recommendations on prevention of coronary heart disease in clinical practice. British Cardiac Society, British Hyperlipidaemia Association, British Hypertension Society, endorsed by the British Diabetic Association. Heart 1998;80(suppl 2):S1-29.

5 Johanneson $M$, Jonsson B, Kjekshus $\mathrm{J}$, et al. Cost effectiveness of simvastatin treatment to lower cholesterol levels in patients with coronary heart disease. $N$ Engl f Med 1997;336:332-6.

6 Ashraf T, Hay JW, Pitt B, et al. Cost-effectiveness of pravastatin in secondary prevention of coronary artery disease. Am f Cardiol 1996;78:409-14.

7 Bowker TJ, Clayton TC, Ingham J, et al. A British Cardiac Society survey of the potential for the secondary prevention of coronary disease: ASPIRE (action on secondary prevention through intervention to reduce events). Heart 1996;75: $334-42$

8 Northridge DB, Shandall A, Rees A, et al. Inadequate management of hyperlipidaemia after coronary bypass surgery shown by medical audit. Br Heart $\mathcal{F}$ 1994;72:466-7.

9 Rees A. Hypercholesterolaemia: secondary prevention. Prescriber's fournal 1999;39:212-19. 